\title{
Pengembangan Media Pembelajaran Matematika Interaktif Berbasis Problem Based Learning di Kelas V SDN 22 Duku Kecamatan Koto XI Tarusan
}

\author{
Syafni Gustina Sari ${ }^{1}$, Ahmad Fauzan $^{2}$, Armiati $^{3}$, Yerizon ${ }^{4}$ \\ ${ }^{1}$ Pendidikan Guru Sekolah Dasar, Universitas Bung Hatta, Jl. Bagindo Aziz Chan ByPass Aie Pacah Padang \\ ${ }^{2,3,4}$ Program Pascasarjana, Universitas Negeri Padang, Jl. Prof. Dr. Hamka, Air Tawar Padang \\ syafnigustinasari@bunghatta.ac.id
}

\begin{abstract}
This research is motivated by the unavailability of interactive mathematics learning media that can be used both online and offline. This study aims to develop an interactive mathematics learning media based on Problem Based Learning in Class V SDN 22 Duku, Koto XI Tarusan District. This type of research is Research and Development (R \& D) with the development model being the plomp development model. The stages carried out in this research are the preliminary study phase, the development phase or prototype making and the assessment phase. This research instrument includes a validation sheet which is validated by 2 experts and a practical response sheet for the fourthgrade students of SD Negeri 22 Duku as many as 21 people. Based on the results of research on the development of interactive mathematics learning media based on Problem Based Learning in Class V SDN 22 Duku, Koto XI Tarusan District, learning media were produced that met the valid criteria with a percentage of $93.7 \%$ and met the practical criteria with a percentage of $88.07 \%$. This shows that the interactive mathematics learning media based on Problem Based Learning in Class V SDN 22 Duku, Koto XI Tarusan District is valid and practical for use in learning mathematics, especially the relationship material between units of length for grade IV students.
\end{abstract}

Keywords: Media Development, Interactive Learning, Mathematics, Problem Based Learning

\begin{abstract}
Abstrak
Penelitian ini dilatarbelakangi oleh belum tersedianya media pembelajaran matematika yang interaktif yang bisa digunakan baik secara online maupun secara offline. Penelitian ini bertujuan untuk mengembangkan media pembelajaran matematika interaktif berbasis Problem Based Learning di Kelas V SDN 22 Duku Kecamatan Koto XI Tarusan. Jenis penelitian adalah penelitian pengembangan atau Research and Development $(R \& D)$ dengan model pengembangannya adalah model pengembangan plomp. Tahapan yang dilakukan pada penelitian ini adalah fase studi pendahuluan, fase pengembangan atau pembuatan prototype dan fase penilaian. Instrumen penelitian ini meliputi lembar validasi yang divalidasi oleh 2 orang ahli dan lembar praktikalitas respon siswa kelas IV SD Negeri 22 Duku sebanyak 21 orang. Berdasarkan hasil penelitian pengembangan media pembelajaran matematika interaktif berbasis berbasis Problem Based Learning di Kelas V SDN 22 Duku Kecamatan Koto XI Tarusan, maka dihasilkan media pembelajaran yang memenuhi kriteria valid dengan persentase $93.7 \%$ dan memenuhi kriteria praktis dengan persentase 88.07\%. Hal ini menunjukkan media pembelajaran matematika interaktif berbasis berbasis Problem Based Learning di Kelas V SDN 22 Duku Kecamatan Koto XI Tarusan valid dan praktis untuk digunakan dalam pembelajaran matematika khususnya materi hubungan antar satuan panjang untuk siswa kelas IV.
\end{abstract}

Kata kunci: Pengembangan Media, Pembelajaran Interaktif, Matematika, Problem Based Learning

Copyright (c) 2021 Syafni Gustina Sari, Ahmad Fauzan, Armiati, Yerizon

$\triangle$ Corresponding author: Syafni Gustina Sari

Email Address: syafnigustinasari@bunghatta.ac.id (Jl. Bagindo Aziz Chan ByPass Aie Pacah Padang)

Received 01 June 2021, Accepted 29 June 2021, Published 26 July 2021

\section{PENDAHULUAN}

Penggunaan media dalam pembelajaran matematika dapat membantu meningkatkan kemampuan menalar siswa, terutama jika menggunakan media yang memanfaatkan teknologi. Sejalan dengan pendapat (Kamarullah, 2017), dengan memiliki kemampuan penalaran matematika yang memadai, diharapkan para peserta didik akan mampu mendalami berbagai disiplin ilmu yang menjadi keahliannya, terutama ilmu yang terkait dengan teknologi. Berdasarkan Permendikbud No. 21 Tahun 2016 tentang standar isi, salah satu 
kompetensi yang ingin dicapai dalam muatan pembelajaran Matematika ditingkat pendidikan dasar adalah menunjukan sikap positif bermatematika: logis, cermat dan teliti, jujur, bertanggung jawab, dan tidak mudah menyerah dalam menyelesaikan masalah, sebagai wujud implementasi kebiasaan dalam inkuiri dan eksplorasi Matematika, serta memliki rasa ingin tahu, semangat belajar yang continue, percaya diri, dan ketertarikan pada Matematika melalui pengalaman belajar (Permendikbud, 2016). Namun kenyataan yang terjadi adalah kompetensi yang diharapkan tersebut banyak yang tidak tercapai, seperti ketertarikan siswa pada matematika melalui pengalaman belajar belum terpenuhi seutuhnya. Sejalan dengan hal itu, Matematika sering dianggap tidak lebih dari sekedar berhitung, bermain dengan rumus dan angka-angka yang membuat pusing siswa. Sebagian besar siswa menganggap matematika sebagai pelajaran yang sukar dan menakutkan, sehingga menjadi momok bagi siswa. Tidak sedikit pula siswa yang merasa tidak minat untuk belajar matematika (Leonard \& U.S, 2010). Matematika merupakan mata pelajaran yang selalu diajarkan mulai dari tingkat yang paling rendah sampai perguruan tinggi.

Pembicaraan kreativitas dalam matematika lebih ditekankan pada aspek prosesnya, yakni proses berpikir kreatif (Mahmudi, 2008). Pembelajaran kreatif merupakan pembelajaran yang mendorong siswa aktif terlibat dalam proses perencanaan, pelaksanaan dan mengevaluasi hasil belajarnya sendiri. Dalam pembelajaran ini, siswa diberi kebebasan dalam mengeksplorasi berbagai sumber yang relevan dengan topik/konsep/masalah yang sedang dipelajari. Dalam hal mengeksplorasi berbagai sumber, tidak tertutup kemungkinan siswa akan melakukan interaksi dengan lingkungan dan pengalamannya sendiri. Eksplorasi dapat dilakukan dengan observasi, diskusi, dan melakukan percobaan. Dengan cara ini, konsep tidak lagi ditransfer kepada siswa melainkan siswa membentuk konsep itu sendiri melalui interaksi dan pengalaman.

Kreativitas dalam berfikir sangat mempengaruhi proses belajar. Seperti dikemukakan di muka bahwa belajar diawali dari proses ingin tahu. Ketika seseorang mempunyai masalah dan ingin menyelesaikannya, Ia akan menggunakan pikirannya untuk melihat fakta-fakta apa saja yang terjadi di sekitarnya yang berhubungan dengan masalah tersebut. Kemudian Ia menghubungkan fakta-fakta yang ada lalu berfikir mencari alternatif penyelesaian sehingga nantinya didapatkan penyelesaian yang diinginkan. (Suherman, 2015). Sifat dasar otentik seperti pembelajaran high-end dengan menciptakan suatu lingkungan di mana siswa menerapkan pengetahuan dan keterampilan yang relevan dengan pemecahan masalah nyata. Adapun karakteristik utama dari pembelajaran yang kreatif adalah menggenggam kesempatan untuk terlibat dalam penyelidikan intelektual, kemungkinan untuk terlibat secara produktif dengan pekerjaan siswa atau kegiatan dan apresiasi yang ditunjukkan untuk meninjau baik konstruksi dan proses produk.

Pada kegiatan pembelajaran tatap muka, media pembelajaran dapat berupa orang, benda-benda sekitar, lingkungan dan segala sesuatu yang dapat digunakan guru sebagai perantara menyampaikan materi pelajaran. Hal tersebut akan menjadi berbeda ketika pembelajaran dilaksanakan secara daring. Semua media atau alat yang dapat guru hadirkan secara nyata, berubah menjadi media visual karena keterbatasan jarak.

Pembelajaran daring dapat dilakukan dengan menggabungkan beberapa jenis sumber belajar seperti dokumen, gambar, video, audio dalam pembelajaran. Materi belajar tersebut dapat dimanfaatkan siswa dengan melihat atau membaca. Sumber belajar seperti inilah yang menjadi modal utama dalam 
Pengembangan Media Pembelajaran Matematika Interaktif Berbasis Problem Based Learning di Kelas V SDN 22 Duku Kecamatan Koto XI Tarusan, Syafni Gustina Sari, Ahmad Fauzan, Armiati, Yerizon

2125

mengembangkan pembelajaran daring, karena jika guru mengemas pembelajaran semenarik mungkindan sesuai dengan karakteristik siswa, maka tujuan pembelajaran dapat tercapai meskipun dalam kegiatan daring.

Sejumlah guru mengalami kendala yang dialami guru ketika melaksanakan pembelajaran daring diantaranya aplikasi pembelajaran, jaringan internet dan gawai, pengelolaan pembelajaran, penilaian, dan pengawasan (Rigianti, 2020). Bagi guru sekolah dasar yang terbisa melakukan pembelajaran secara tatap muka, kondisi ini memunculkan ketidaksiapan persiapan pembelajaran.Perubahan yang terjadi secara cepat dan mendadak sebagai akibat penyebaran Covid-19 membuat semua orang dipaksa untuk melek teknologi (Rigianti, 2020).

Sejalan dengan pendapat di atas, (Suhery et al., 2020) menyatakan bahwa proses pembelajaran daring cenderung hanya berorientasikan tugas. Dari hasil penelitian yang dilakukan oleh (Taradisa et al., 2020)diperoleh hasil bahwa kekurangan dari pembelajaran daring adalah Pemahaman siswa terhadap materi kurang, Guru sulit memantau perkembangan belajar siswa, Berkurangnya interaksi antara guru dan siswa.

Pembelajaran daring di rasa sangat kurang efektif bagi guru terutama untuk anak usia sekolah dasar, karena pembelajaran yang dilakukan secara daring atau pembelajaran jarak jauh yang dilakukan dirumah tersebut, maka guru juga kurang maksimal dalam memberikan materi pembelajaran. Sehingga menjadikan materi tidak tuntas dan penggunaan media pembelajaran dalam pembelajaran daring juga dirasa tidak maksimal(Sari et al., 2021). Beberapa dampak yang dirasakan murid yaitu murid belum ada budaya belajar jarak jauh karena selama ini sistem belajar dilaksanakan adalah melalui tatap muka, murid terbiasa berada di sekolah untuk berinteraksi dengan teman-temannya, bermain dan bercanda gurau dengan temantemannya serta bertatap muka dengan para gurunya, dengan adanya metode pembelajaran jarah jauh membuat para murid perlu waktu untuk beradaptasi dan mereka menghadapi perubahan baru yang secara tidak langsung akan mempengaruhi daya serap belajar mereka (Dewi, 2020). Kelemahan dalam pembelajaran daring adalah kurang maksimalnya keterlibatan siswa.(Anugrahana, 2020).

Penyusunan materi dan penggunaan alat media pembelajaran yang digunakan pada proses pembelajaran daring yangdilakukan oleh pendidik dan peserta didik harus disesuaikan dengan tingkat perkembangan intelektual peserta didik, hal ini dilakukan agar peserta didik lebih mudah memahami materimateri yang diberikan(Wiryanto, 2020). Jika dibiarkan, Proses pembelajaran daring dilakukan agar kegiatan pendidikan di negara Indonesia bisa terus berjalan dengan efektif dan dapat meningkatkan kualitas pendidikan pada masa pandemi Covid-19, terutama untuk peserta didik MI/SD akan terus mendapatkan materi pelajaran dari gurunya sehingga para peserta didik tidak tertinggal dalam proses pendidikannya (Qoriawati, 2021).

Media pembelajaran berbasis TIK dapat melatih kemandirian siswa. Siswa dapat belajar secara mandiri tanpa harus disertai peranseorang guru. Siswa dapat berinteraksi dengan media seperti halnya berinteraksi dengan guru. Media semacam ini disebut media interaktif (Widjayanti et al., 2018). Media pembelajaran interaktif menggunakan gambar, animasi, dan audio yang dirancang semenarik mungkin agar siswa tertarik untuk menggunakan media tersebut. Media pembelajaran interaktif dapat digunakan sebagai 
media pengajaran yang efektif dengan fasilitas multimedia yang berupa gambar, suara dan animasi sehingga siswa lebih mudah memahami materi yang disampaikan (Maryani, 2014).

Pemanfaatan media interaktif akan lebih baik jika dalam pemaparan materinya juga menggunakan sebuah model yang menuntun dalam menjelaskan materi kepada siswa. Salah satu model pembelajaran yang digunakan dalam pemanfaatan media ini adalah dengan menggunakan model Problem Based Learning (PBL). Pemanfaatan media dalam pembelajaran memberikan banyak manfaat bagi siswa. Adanya media membuat siswa dapat berpikir secara konkrit tentang materi yang disampaikan guru (Frianto et al., 2018). Model Problem Based Learning penting diterapkan dalam pembelajaran matematika, karena melalui model ini siswa dapat melatih keterampilan berpikirnya untuk memecahkan permasalahan yang diberikan oleh guru di kelas. Ciri-ciri pembelajaran problem based learning (PBL) yaitu menerapkan pembelajaran yang kontekstual, masalah yang disajikan dapat memotivasi siswa peserta didik untuk belajar, pembelajaran integritas yaitu pembelajaran termotivasi dengan masalah yang tidak terbatas, siswa terlibat secara aktif dalam pembelajaran, kolaborasi kerja, peserta didik memiliki berbagai keterampilan, pengalaman, dan berbagai konsep (Fauzia, 2018). Jadi, dengan memanfaatkan media pembelajaran interaktif berbasis Problem based Learning (PBL) dapat membuat siswa termotivasi dan nisa belajar secara mandiri.

Oleh sebab itu, maka penelitian ini mengembangkan media pembelajaran matematika interaktif berbasis Problem Based Learning di Kelas V SDN 22 Duku Kecamatan Koto XI Tarusan. Penelitian ini dapat bermanfaat baik bagi guru maupun kepala sekolah sebagai bahan pertimbangan untuk pelaksanaan pembelajaran baik dilakukan secara daring maupun secara luring. Media ini juga bisa dijadikan sebagai bahan referensi dalam pembelajaran yang dilakukan secara daring dan luring. Selain itu, media ini juga di desain sesuai dengan kebutuhan dan karakteristik siswa SD sehingga siswa tertarik dan termotivasi untuk belajar.

\section{METODE}

Jenis penelitian adalah penelitian pengembangan atau Research and Development $(R \& D)$ dengan model pengembangannya adalah model pengembangan Plomp. Tahapan yang dilakukan pada penelitian ini adalah fase studi pendahuluan, fase pengembangan atau pembuatan prototype dan fase penilaian. Prosedur pengembangan media pembelajaran matematika interaktif berbasis penemuan terbimbing menggunakan aplikasi articulate storyline pada materi hubungan antar satuan panjang untuk kelas III Sekolah Dasar, mengacu kepada model pengembangan Plomp dengan melaksanakan 3 fase pengembangan, diantaranya adalah : Fase Studi Pendahuluan (Preliminary Study), Fase Pengembangan atau Pembuatan Prototype (Development or Prototyping Phase) dan Fase Penilaian (Assesment Phase).

Instrumen pengumpulan data yang digunakan dalam penelitian ini adalah lembar validasi yang divalidasi oleh ahli dan lembar praktikalitas yang diisi oleh siswa setelah melakukan uji coba media pembelajaran matematika interaktif berbasis problem based learning. Metode pengumpulan data yang dipakai dalam penelitian ini adalah metode deskriptif dan observasi. Metode Penelitian Deskriptif (descriptive research) digunakan untuk mendeskripsikan suatu keadaan atau fenomena-fenomena apa 
Pengembangan Media Pembelajaran Matematika Interaktif Berbasis Problem Based Learning di Kelas V SDN 22 Duku Kecamatan Koto XI Tarusan, Syafni Gustina Sari, Ahmad Fauzan, Armiati, Yerizon

2127

adanya (Abidin \& Purbawanto, 2015). Adapun teknik analisis data yang digunakan dalam penelitian ini adalah teknik analisis statistik deskriptif yakni dengan menggambarkan secara gamblang perolehan data tentang karakteristik dari masing-masing variabel. pada lembar validitas, dengan rumusnya yaitu : Skor maksimum $=$ jumlah validator $\times$ jumlah indikator $\times$ skor maksimum penilaian. Data hasil praktikalitas diperoleh dengan cara menghitung skor siswa yang telah menjawab masing-masing item yang terdapat dalam lembar angket.

\section{HASIL}

Pembelajaran menggunakan media sudah dilakukan selama pembelajaran daring karena covid-19. Media yang digunakan oleh guru adalah dengan menggunakan media sosial berupa whatsapp. Sebagian dari orangtua juga menjemput langsung ke sekolah soal-soal yang akan dikerjakan oleh anaknya. Guru cenderung memberikan soal-soal dan tugas orangtua untuk mengajarkan ke anaknya di rumah. Sebelum penggunaan media pembelajaran interaktif diberikan, siswa diminta mengisi angket tentang persepsi media yang selama ini diberikan. Hasil angket dapat dilihat pada tabel di bawah ini:

Tabel 1. Analisis Hasil Angket Sebelum Penggunaan Media

\begin{tabular}{|l|l|c|}
\hline No & \multicolumn{1}{|c|}{ Pernyataan } & \multicolumn{1}{|c|}{ Persentase } \\
\hline 1 & $\begin{array}{l}\text { Saya belum pernah mencoba belajar menggunakan media } \\
\text { pembelajaran yang memberikan respon terhadap apa yang saya } \\
\text { masukkan. }\end{array}$ & $53,57 \%$ \\
\hline 2 & $\begin{array}{l}\text { Saya lebih suka belajar dengan metode ceramah dari pada } \\
\text { metode lain apalagi menggunakan media pembelajaran }\end{array}$ & $84,52 \%$ \\
\hline 3 & $\begin{array}{l}\text { Pembelajaran menggunakan media membuat saya bingung } \\
\text { dalam memahami materi }\end{array}$ & $61,90 \%$ \\
\hline 4 & Media tidak melatih saya untuk belajar mandiri & $63,09 \%$ \\
\hline 5 & Pembelajaran tetap efektif walaupun tidak menggunakan media & $77,38 \%$ \\
\hline 6 & $\begin{array}{l}\text { Pembelajaran tanpa menggunakan media membuat saya senang } \\
\text { mengikuti pembelajaran }\end{array}$ & $54,76 \%$ \\
\hline 7 & $\begin{array}{l}\text { Saya sering tidak memperhatikan guru ketika menjelaskan } \\
\text { materi menggunakan papan tulis }\end{array}$ & $53,57 \%$ \\
\hline 8 & $\begin{array}{l}\text { Saya ingin belajar menggunakan media pembelajaran yang } \\
\text { menarik sepertia memiliki gambar, suara dan animasi }\end{array}$ & $80,95 \%$ \\
\hline 9 & $\begin{array}{l}\text { Saya akan bersemangat jika belajar menggunakan media yang } \\
\text { menarik }\end{array}$ & $77,38 \%$ \\
\hline 10 & $\begin{array}{l}\text { Pembelajaran akan lebih menyenangkan jika menggunakan } \\
\text { media pembelajaran yang menarik }\end{array}$ & $78,57 \%$ \\
\hline
\end{tabular}

Dari tabel 1 dapat disimpulkan bahwa siswa kelas V SDN 22 Duku sudah pernah menggunakan media pembelajaran namun kurang disukai oleh mereka. Dalam penggunaan media, persentase yang mengatakan tidak melatih siswa untuk belajar mandiri hanya 63,09\%. Ini berarti bahwa media yang digunakan belum terlalu mampu melatih siswa untuk belajar mandiri. Jika ditanya mengenai apakah pembelajaran tetap efektif walaupun tidak menggunakan media, mereka cenderung menjawab tidak setuju 
yaitu dengan persentase 77,38\%. Mereka merasa senang saja ketika tidak menggunakan media. Ketika guru menjelaskan materi hanya menggunakan papan tulis, mereka juga tidak terlalu memperhatikan. Siswa tersebut lebih cenderung ingin menggunakan media pembelajaran yang menarik seperti memiliki gambar, suara dan animasi. Mereka menyatakan akan bersemangat dan merasa senang jika media yang digunakan gurunya menarik. Jadi dapat disimpulkan bahwa interpretasi siswa terhadap penggunaan media termasuk dalam kategori sedang.hal ini dikarenakan media yang digunakan belum interaktif atau hanya berlaku satu arah saja.

Media pembelajaran interaktif berbasis Problem Based Learning (PBL) pada mata pelajaran Matematika dibuat dengan mengacu kepada kurikulum 2013. Media pembelajaran interaktif ini dibuat dengan menggunakan aplikasi Articulate Storyline dengan tujuan agar siswa aktif dan tertarik untuk belajar. Media pembelajaran matematika interaktif yang dikembangkan dilengkapi dengan gambar dan animasi yang menarik, menu-menu dan tombol-tombol yang aktif serta memuat suara, latihan, dan hasil evaluasi dari latihan tersebut, sehingga media pembelajaran ini dapat membuat siswa menjadi tertarik dan tertantang untuk mengikuti pembelajaran. Cuplikan gambar dapat di lihat pada Gambar 1, 2 dan 3.

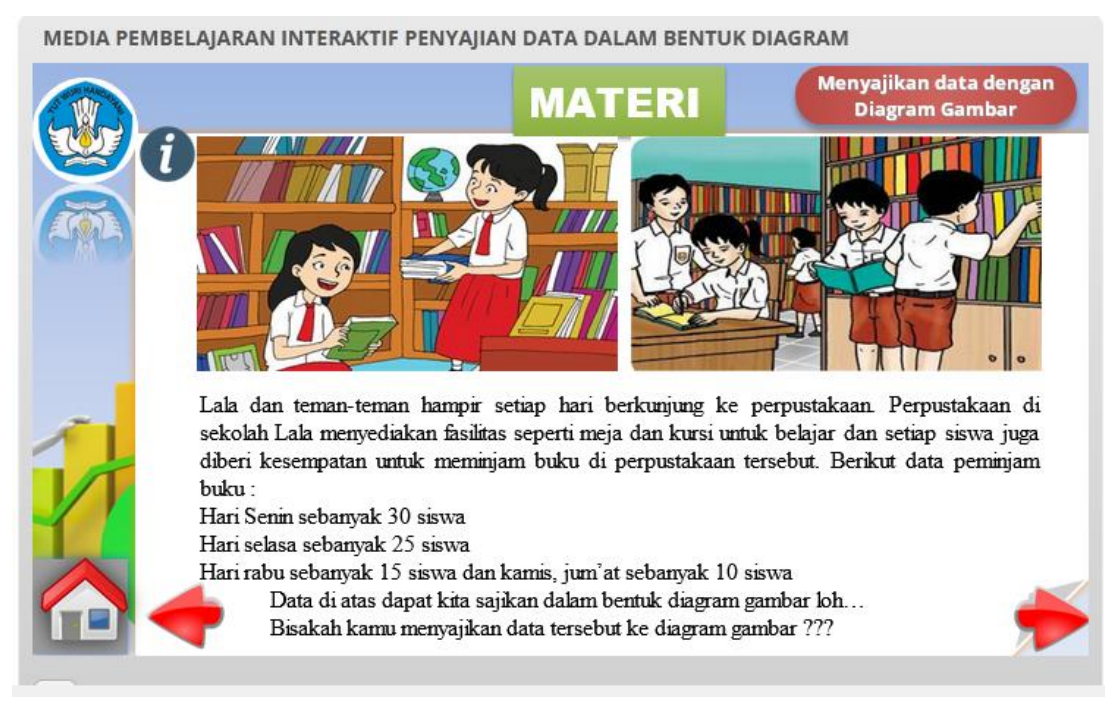

Gambar 1. Mengorientasikan peserta didik terhadap masalah

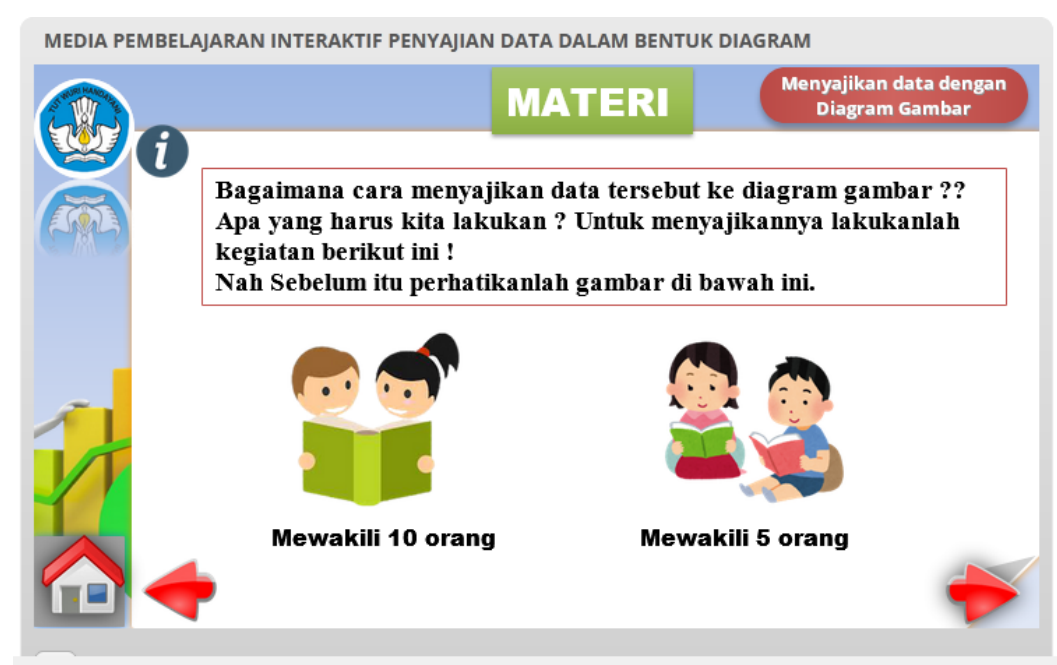

Gambar 2. Mengorganisasikan peserta didik untuk belajar 
Pengembangan Media Pembelajaran Matematika Interaktif Berbasis Problem Based Learning di Kelas V SDN 22 Duku Kecamatan Koto XI Tarusan, Syafni Gustina Sari, Ahmad Fauzan, Armiati, Yerizon

2129

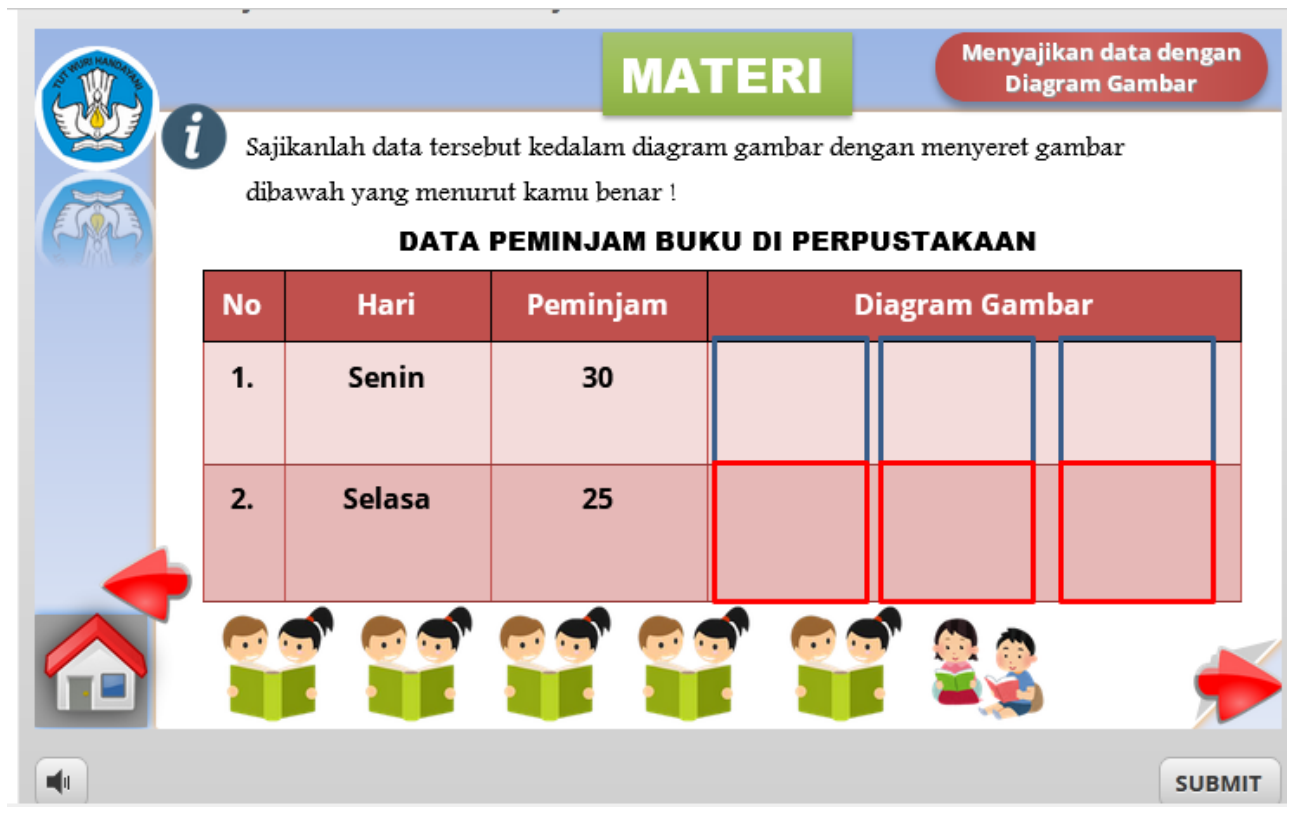

Gambar 3. Membimbing penyelidikan individu, Mengembangkan dan menyajikan hasil karya dan Menganalisis dan mengevaluasi

Hasil analisis validasi media pembelajaran matematika interaktif berbasis Problem Based Learning di Kelas V SDN 22 Duku Kecamatan Koto XI Tarusan dapat dilihat pada Tabel 2.

Tabel 2. Hasil Analisis validasi media

\begin{tabular}{|c|l|l|l|l|l|}
\hline No & Aspek Penilaian & Jumlah Skor & $\begin{array}{c}\text { Skor } \\
\text { Maksimum }\end{array}$ & Persentase & Kategori \\
\hline 1 & Materi & 38 & 40 & $95 \%$ & Sangat valid \\
\hline 2 & Tampilan Media & 37 & 40 & $95,2 \%$ & Sangat Valid \\
\hline
\end{tabular}

Dari tabel 2 diatas daiperoleh bahwa rata-rata persentase validasi media pembelajaran matematika interaktif berbasis Problem Based Learning di Kelas V SDN 22 Duku Kecamatan Koto XI Tarusan adalah 93,7\% dengan kategori sangat valid. Untuk mengetahui tingkat pencapaian itu maka diberikanlah angket praktikalitas kepada siswa tentang persepsi setelah menggunakan media pembelajaran interaktif tersebut. Hasil analisis angket tersebut dapat dilihat pada tabel 2 di bawah ini:

Tabel 3. Analisis Angket praktikalitas Siswa menggunakan media pembelajaran interaktif berbasis Problem Based Learning (PBL) pada pembelajaran Matematika

\begin{tabular}{|c|c|c|}
\hline No & Indikator & Persentase \\
\hline 1 & Kemudahan penggunaan media & $89,29 \%$ \\
\hline 2 & Efektifitas Waktu & $84,92 \%$ \\
\hline 3 & Daya Tarik Media & $90 \%$ \\
\hline
\end{tabular}

Rincian dari indikator pada tabel dapat dilihat pada tabel 3 di bawah ini:

Tabel 4. Rincian Hasil analisis Angket Praktikalitas Siswa

\begin{tabular}{|c|l|c|}
\hline No & \multicolumn{1}{|c|}{ Pernyataan } & Persentase \\
\hline 1 & Petunjuk penggunaan media dapat dipahami dengan jelas & $90,48 \%$ \\
\hline 2 & $\begin{array}{l}\text { Uraian materi dalam media menuntun kamu dalam } \\
\text { memahami materi }\end{array}$ & $86,90 \%$ \\
\hline
\end{tabular}




\begin{tabular}{|c|l|l|}
\hline 3 & $\begin{array}{l}\text { Penyajian materi dalam media lebih praktis dan dapat } \\
\text { dipelajari berulang-ulang }\end{array}$ & $90,48 \%$ \\
\hline 4 & $\begin{array}{l}\text { Media dapat melatih kamu untuk belajar mandiri karena } \\
\text { dapat digunakan dengan mudah dan dimana saja }\end{array}$ & $73,81 \%$ \\
\hline 5 & Pembelajaran menjadi efektif dengan penggunaan media & $91,67 \%$ \\
\hline 6 & Penyusunan materi pada materi tersusun secara sistematis & $85,71 \%$ \\
\hline 7 & Media memiliki tampilan yang menarik & $94,05 \%$ \\
\hline 8 & Gambar dan animasi yang ada di dalam media menarik & $90,48 \%$ \\
\hline 9 & Materi yang disampaikan pada media mudah saya pahami & $89,29 \%$ \\
\hline 10 & $\begin{array}{l}\text { Saya menjadi bersemangat untuk belajar dengan } \\
\text { menggunakan media ini }\end{array}$ & $90,48 \%$ \\
\hline
\end{tabular}

Berdasarkan tabel 4 di atas, dapat diketahui bahwa petunjuk penggunaan media dapat dipahami dengan jelas. Uraian materi dalam media pembelajaran dapat menuntun siswa dalam memahami materi pelajaran karena dalam perancangan media, diprioritaskan adalah adanya interaktif dan pemaparan materi menggunakan langkah Problem Based Learning (PBL). Media interaktif yang dirancang juga sangat praktis dan bisa dipelajari berulang-ulang karena media interaktif ini bisa dimanfaatkan guru dan siswa baik secara offline maupun secara online. Media ini juga bisa dibuka di laptop/PC maupun di android sehingga siswa bisa belajar secara mandiri dan membuka dimana saja dan kapan saja. Penyusunan materi dilakukan secara sistematis dan menggunakan langkah model PBL. Model Pembelajaran Berbasis Masalah (Problem Based Learning) Pembelajaran berbasis masalah merupakan suatu model pembelajaran yang menantang peserta didik untuk "belajar bagaimana belajar", bekerja secara berkelompok untuk mencari solusi dari permasalahan dunia nyata. Masalah yang diberikan ini digunakan untuk mengikat peserta didik pada rasa ingin tahu pada pembelajaran yang dimaksud(Kistian, 2019).Tampilan media di desain menarik sesuai dengan karakter siswa agar mereka tertarik untuk berlama-lama dalam menggunakan media. Gambar dan animasinya juga dibuat semenarik mungkin agar siswa tidak bosan. Pemaparan media juga dibuat dalam bentuk yang sederhana mulai dari yang mudah sampai yang sulit. Termasuk didalamnya siswa dituntun untuk menggunakan media tersebut. Sehingga siswa bersemangat menggunakan media interaktif ini.

\section{KESIMPULAN}

Berdasarkan data yang diperoleh dapat disimpulkan bahwa media pembelajaran matematika interaktif berbasis Problem Based Learning di Kelas V SDN 22 Duku Kecamatan Koto XI Tarusan valid dan praktis. Selain itu, terdapat 3 aspek indikator yang menjadi sudut pandang siswa terhadap penggunaan media pembelajaran interaktif berbasis Problem Based Learning (PBL) pada mata pelajaran Matematika, yaitu Kemudahan penggunaan media mendapatkan respon sangat setuju dalam kategori sangat baik yaitu sebanyak $89,29 \%$, Efektifitas Waktu mendapatkan respon setuju dalam kategori baik yaitu sebanyak $84,92 \%$, Daya tarik media mendapatkan respon setuju dalam kategori sangat baik yaitu sebanyak $90 \%$. Dengan demikian Persepsi Siswa Terhadap Penggunaan media pembelajaran interaktif berbasis Problem Based Learning (PBL) pada mata pelajaran Matematika di Kelas VSDN 22 Duku Kecamatan Koto XI Tarusan sebagai sampel mendapatkan tanggapan yang baik. 
Pengembangan Media Pembelajaran Matematika Interaktif Berbasis Problem Based Learning di Kelas V SDN 22 Duku Kecamatan Koto XI Tarusan, Syafni Gustina Sari, Ahmad Fauzan, Armiati, Yerizon

2131

\section{REFERENSI}

Abidin, Z., \& Purbawanto, S. (2015). MEDIA. Edu Elektrika Journal, 4(1), 38-49.

Anugrahana, A. (2020). Hambatan, Solusi dan Harapan: Pembelajaran Daring Selama Masa Pandemi Covid-19 Oleh Guru Sekolah Dasar. Jurnal Scholaria, 10(3), 282-289.

Dewi, W. A. F. (2020). Dampak COVID-19 terhadap Implementasi Pembelajaran Daring di Sekolah Dasar. Edukatif: Jurnal Ilmu Pendidikan, 2(1), 55-61. https://doi.org/10.31004/edukatif.v2i1.89

Fauzia, H. A. (2018). Penerapan Model Pembelajaran Problem Based Learning Untuk Meningkatkan Hasil Belajar Matematika Sd. Primary: Jurnal Pendidikan Guru Sekolah Dasar, 7(1), 40. https://doi.org/10.33578/jpfkip.v7i1.5338

Frianto, O., Relmasira, S. C., \& Hardini, A. T. A. (2018). Meningkatkan Kemampuan Pemecahan Masalah Matematika melalui Penerapan Model Pembelajaran Problem Based Learning (PBL) berbantuan Media Realia pada Siswa Kelas IV SD. International Journal of Elementary Education, 2(4), 348. https://doi.org/10.23887/ijee.v2i4.16115

Kamarullah, K. (2017). Pendidikan Matematika Di Sekolah Kita. Al Khawarizmi: Jurnal Pendidikan Dan Pembelajaran Matematika, 1(1), 21. https://doi.org/10.22373/jppm.v1i1.1729

Kistian, A. (2019). Penerapan Model Pembelajaran Problem Based Learning (PBL) dalam Meningkatkan Hasil Belajar Siswa Kelas IV SD Negeri Ujong Tanjong Kabupaten Aceh Barat. Genta Mulia, X(1), 92-104.

Leonard, \& U.S, S. (2010). Pengaruh Konsep Diri, Sikap Siswa Pada Matematika, Dan Kecemasan Siswa Terhadap Hasil Belajar Matematika. Cakrawala Pendidikan, 29(3), 259-262. https://doi.org/10.1007/s002669900030

Mahmudi, A. (2008). Tinjauan Kreativitas dalam Pembelajaran Matematika. Pythagoras: Jurnal Pendidikan Matematika, 4(2), 37-49. https://doi.org/10.21831/pg.v4i2.559

Maryani, D. (2014). Pembuatan Media Pembelajaran Interaktif Bangun Ruang Matematika. 12(1), 18-24. Permendikbud. (2016). Peraturan Mentr. Standar Isi Pendidikan Dasar Dan Menengah, 1-168.

Qoriawati, U. (2021). Upaya Peningkatan Kualitas Pembelajaran Daring bagi Peserta Didik MI/SD pada Masa Pandemi Covid-19. JEMARI (Jurnal Edukasi Madrasah Ibtidaiyah), 3(1), 10-17. https://doi.org/10.30599/jemari.v3i1.769

Rigianti, H. A. (2020). Kendala Pembelajaran Daring Guru Sekolah Dasar Di Di Kabupaten Banjarnegara. Elementary School, 7(2), 297-302.

Sari, R. P., Tusyantari, N. B., \& Suswandari, M. (2021). Dampak Pembelajaran Daring Bagi Siswa Sekolah Dasar Selama Covid-19. Prima Magistra: Jurnal Ilmiah Kependidikan, 2(1), 9-15. https://doi.org/10.37478/jpm.v2i1.732

Suherman. (2015). Kreativitas Siswa Dalam Memecahkan Masalah Matematika Materi Pola Bilangan dengan Pendekatan Matematika Realistik (PMR) Suherman. Al-Jabar: Jurnal Pendidikan Matematika, 6(1), 81-90.

Suhery, S., Putra, T. J., \& Jasmalinda, J. (2020). Sosialisasi Penggunaan Aplikasi Zoom Meeting Dan 
Google Classroom Pada Guru Di Sdn 17 Mata Air Padang Selatan. Jurnal Inovasi Penelitian, 1(3), 129-132. https://doi.org/10.47492/jip.v1i3.90

Taradisa, N., Jarmita, N., \& Emalfida. (2020). Kendala Yang Dihadapi Guru Mengajar Daring Pada Masa Pandemi COvid 19 MIN 5 Banda Aceh. UIN Ar-Raniry Banda Aceh, 1(1), 23.

Widjayanti, W. R., Masfingatin, T., \& Setyansah, R. K. (2018). Media Pembelajaran Interaktif Berbasis Animasi Pada Materi Statistika Untuk Siswa Kelas 7 Smp. Jurnal Pendidikan Matematika, 13(1), 101-112. https://doi.org/10.22342/jpm.13.1.6294.101-112

Wiryanto. (2020). Proses Pembelajaran Matematika Di Sekolah Dasar Di Tengah Pandemi Covid-19. Jurnal Review Pendidikan Dasar: Jurnal Kajian Pendidikan Dan Hasil Penelitian, 6(2), 125-132. 